\title{
Evaluation of complications of abdominal and vaginal hysterectomy
}

\author{
N. Fatima Shanthini, G. K. Poomalar*, M. Jayasree, A. Bupathy
}

Department of Obstetrics \& Gynaecology, Sri Manakula Vinayagar Medical College Hospital, Pondicherry, India

Received: 20 November 2012

Revised: 5 December 2012

Accepted: 13 December 2012

*Correspondence:

Dr. G. K. Poomalar,

E-mail: poomalarpragash@gmail.com

\begin{abstract}
Background: Hysterectomy is one of the most common surgical procedures performed by the gynaecologist. It can be performed by vaginal and abdominal route. Gynaecologic surgeons worldwide continue to use the abdominal approach for a large majority of hysterectomies that could be performed vaginally despite well-documented evidence that vaginal hysterectomy has better outcome. Aim of our study is to compare vaginal route versus abdominal route of hysterectomy in terms of intra operative and post operative complications.

Methods: A retrospective study was done in 229 women who had undergone hysterectomy (176 abdominal hysterectomies and 53 vaginal hysterectomies) from January 2010 to July 2012. Information on the indications, operative procedures, and complications were extracted and analysed.

Results: The mean duration of surgery in $\mathrm{VH}$ group was 79.6 min and that of TAH group was 99.2 min. The mean blood loss was also more in case of TAH group than that of VH group $(215 \mathrm{ml} v \mathrm{vs} .167 \mathrm{ml})$. Bladder injury occurred in 1 case in VH (1.9\%) and in 4 cases in TAH $(2.3 \%)$. Ureter injury occurred in $1(0.6 \%)$ case in TAH group. Wound infection developed in 10 cases of TAH group whereas only one case in VH group developed vault infection.

Conclusions: Vaginal hysterectomy is associated with quicker recovery, early mobilization, shorter hospitalization, less operative and post operative morbidity when compared to abdominal hysterectomy.
\end{abstract}

Keywords: Abdominal hysterectomy, benign uterine diseases, intra operative complications, post operative complications, vaginal hysterectomy

\section{INTRODUCTION}

Hysterectomy is one of the most common surgical procedures performed by the gynaecologist. It can be performed by abdominal and vaginal route. Vaginal hysterectomy ( $\mathrm{VH})$ has several advantages over abdominal hysterectomy (TAH), and may be appropriate for up to $80 \%$ of benign uterine conditions. ${ }^{1,2}$ Evidence supports TAH only when documented pathologic conditions preclude the vaginal route. ${ }^{3,4}$ Even recent study in United States shows $82 \%$ were TAH, only $13 \%$ were $\mathrm{VH}$ and $5 \%$ were laparoscopic assisted in teaching hospitals. ${ }^{5}$ Aim of our study is to compare between vaginal route versus abdominal route of hysterectomy in terms of intra operative and post operative complications.

\section{METHODS}

A retrospective study was done in department of Obstetrics and Gynaecology of Sri Manakula Vinayagar Medical College and Hospital in Puducherry, India from January 2010 to July 2012. Study was done in women who had undergone vaginal or abdominal hysterectomy in that period. Women in any age group who underwent vaginal or abdominal hysterectomy for benign conditions were included in the study. Women who underwent hysterectomy for uterine prolapse, indications that would generally require an abdominal approach such as endometriosis, pelvic inflammatory disease were excluded from the study. Vaginal hysterectomy was done in those with uterine size $\leq 14$ weeks, unrestricted uterine mobility, and absence of adnexal pathology.

Information such as clinical history, physical examination findings, haemoglobin level preoperatively, indication for 
surgery, operation details, duration of surgery, estimated blood loss at the time of surgery, whether blood transfusion was done in intra operative \& post operative period, intra operative complications like bladder, ureter, bowel injury were collected. Postoperative details like paralytic ileus, burst abdomen, wound infection, length of analgesic usage and hospital stay after surgery were extracted from case sheet. With all these details comparison was made between vaginal and abdominal routes of hysterectomies.

Results are reported as the mean and standard deviation. Comparisons of means were carried out using the Student's $t$-test. Categorical variables were compared using the $\chi^{2}$-test. A two tailed $p$-value below 0.05 was considered significant.

\section{RESULTS}

One hundred and seventy six cases of TAH were performed during study period. 53 cases of $\mathrm{VH}$ performed during study period. Age distribution of cases studied were $25.3 \%$ in between 30 - 39 years, $65.5 \%$ in between 40 - 49 years and $9.2 \%$ in between 50 - 59 years (Table 1). In study group $2.2 \%$ were nulliparous women, $91.7 \%$ were multiparous women (Table 2). Indications for hysterectomies were shown in Table 3 .

Table 1: Age distribution.

\begin{tabular}{|ccc|c|}
$\begin{array}{c}\text { Age } \\
\text { distribution } \\
\text { (years) }\end{array}$ & $\begin{array}{c}\text { VH } \\
(\boldsymbol{n}=\mathbf{5 3})\end{array}$ & $\begin{array}{c}\text { TAH } \\
(\boldsymbol{n}=\mathbf{1 7 6})\end{array}$ & $\begin{array}{c}\text { Total } \\
(\boldsymbol{n}=\mathbf{2 2 9})\end{array}$ \\
\hline $30-39$ & 18 & 40 & $58(25.3 \%)$ \\
\hline $40-49$ & 31 & 119 & $150(65.5 \%)$ \\
\hline $50-59$ & 4 & 17 & $21(9.2 \%)$ \\
\hline
\end{tabular}

Table 2: Parity wise distribution.

\begin{tabular}{|cccc|}
\hline Parity & $\begin{array}{c}\text { VH } \\
(\boldsymbol{n}=\mathbf{5 3})\end{array}$ & $\begin{array}{c}\text { TAH } \\
(\boldsymbol{n}=\mathbf{1 7 6})\end{array}$ & $\begin{array}{c}\text { Total } \\
(\boldsymbol{n}=\mathbf{2 2 9})\end{array}$ \\
\hline Nulliparous & 1 & 4 & $5(2.1 \%)$ \\
\hline Para 1 & 2 & 12 & $14(6.1 \%)$ \\
\hline Para 2 & 22 & 71 & $93(40.6 \%)$ \\
\hline Para 3 & 23 & 60 & $83(36.24 \%)$ \\
\hline Para 4 & 5 & 26 & $31(13.5 \%)$ \\
\hline Para 5 & 0 & 3 & $3(1.3 \%)$ \\
\hline
\end{tabular}

The mean duration of surgery in VH group was $79.6 \mathrm{~min}$ and that of TAH group was $99.2 \mathrm{~min}$ (Table 4). The difference between two groups was statistically significant $(p<0.0001)$. Five cases in TAH group required conversion from spinal anaesthesia to general anaesthesia. None of the cases required conversion of anaesthesia in VH group. Conversion was required due to loss of relaxation due to prolonged surgery, improper visualisation of pelvis leading to difficulty in identifying bleeders. The mean blood loss was also more in TAH group than that of $\mathrm{VH}$ group $(215 \mathrm{ml}$ vs. $167 \mathrm{ml})$ difference is statistically significant $p<0.0001$ (Table 4). Blood loss was heavy in 3 cases of TAH group requiring blood transfusion intraoperatively. None of the cases in VH group had heavy bleeding requiring intra operative blood transfusion. Mean drop in haemoglobin with surgery in VH group was $0.63 \%$, whereas drop was $0.92 \%$ with TAH group (Table 4 ). The difference between two groups was statistically significant $(p<$ $0.0001)$.

Table 3: Indications for hysterectomy.

\begin{tabular}{|ccc|}
\hline $\begin{array}{c}\text { Indications for } \\
\text { hysterectomy }\end{array}$ & VH & TAH \\
\hline Adenomyosis & 7 & 33 \\
\hline DUB & 27 & 38 \\
\hline Fibroid uterus & 18 & 97 \\
\hline $\begin{array}{c}\text { Post menopausal } \\
\text { bleeding }\end{array}$ & 1 & 8 \\
\hline
\end{tabular}

Among intra operative complications, bladder injury occurred in 1 case in VH group (1.9\%) which was diagnosed intra operatively and repaired (Table 5). Bladder injury occurred in 4 cases in TAH group $(2.3 \%)$. Out of it 2 cases were diagnosed intraoperatively and repaired, other 2 case developed vesico vaginal fistula. None of the cases in vaginal group had ureter injury whereas injury occurred in $1(0.6 \%)$ case in TAH group, which was diagnosed in $2^{\text {nd }}$ week of surgery. Intra peritoneal bleeding was diagnosed in $3(1.7 \%)$ cases in $\mathrm{TAH}$ in the postoperative period for which relaparotomy was done (Table 5). None of VH group had such intra peritoneal bleeding.

Postoperatively, 3 cases developed paralytic ileus in TAH group. Similarly in abdominal group 1 case developed burst abdomen \& 2 cases developed rectus sheath hematoma. Wound infection developed in 10 cases of TAH group whereas only one case in VH group developed vault infection. On an average TAH group required analgesics for 9 days. $\mathrm{VH}$ group required analgesics for 5 days. Difference is statistically significant. Duration of hospital stay was also significantly longer in TAH group than $\mathrm{VH}$ group (Table 6).

\section{DISCUSSION}

It is well known fact in spite of several recommendations, $70-80 \%$ of hysterectomies done for benign conditions are through abdominal route. The reason behind this is inadequate technical skills, presence of uterine enlargement makes vaginal route difficult. But with newer techniques like bisection, morcellation and 
Table 4: Duration of surgery and blood loss during surgery.

\begin{tabular}{|c|c|c|c|c|c|c|}
\hline & \multicolumn{2}{|c|}{ VH $(n=53)$} & \multicolumn{2}{|c|}{ TAH $(n=176)$} & \multirow{2}{*}{ t value } & \multirow{2}{*}{$p$ Value } \\
\hline & Mean & SD & Mean & SD & & \\
\hline $\begin{array}{l}\text { Duration of surgery } \\
\text { (minutes) }\end{array}$ & 79.6 & 13.86 & 99.2 & 11.69 & 10.235 & $<0.0001^{*}$ \\
\hline Blood loss (ml) & 167.2 & 57.08 & 215.1 & 77.84 & 4.15 & $<0.0001^{*}$ \\
\hline $\begin{array}{l}\text { Difference in pre and } \\
\text { post operative } \mathrm{Hb} \\
(\mathrm{gm} \%)\end{array}$ & 0.63 & 0.43 & 0.92 & 0.46 & 4.083 & $<0.0001^{*}$ \\
\hline
\end{tabular}

Table 5: Complications of hysterectomy.

\begin{tabular}{|ccccc|}
\hline & VH $(\boldsymbol{n}=\mathbf{5 3})$ & TAH $(\boldsymbol{n = 1 7 6 )}$ & $\chi^{\mathbf{2}}$ value & $p$ Value \\
\hline Bladder injury & 1 & 4 & 0.028 & 0.866 \\
\hline Ureter injury & 0 & 1 & 0.302 & 0.582 \\
\hline Relaparotomy & 0 & 3 & 0.915 & 0.339 \\
\hline Paralytic ileus & 0 & $3(1.7 \%)$ & 0.915 & 0.339 \\
\hline Burst abdomen & 0 & $1(0.57 \%)$ & 0.302 & 0.582 \\
\hline Rectus sheath hematoma & 0 & $2(1.1 \%)$ & 0.608 & 0.436 \\
\hline Wound infection & 0 & $10(5.7 \%)$ & 3.148 & 0.076 \\
\hline Vault infection & $1(1.9 \%)$ & 0 & 3.34 & 0.068 \\
\hline
\end{tabular}

Table 6: Recovery following hysterectomy.

\begin{tabular}{|ccccccc|}
\hline & \multicolumn{2}{c}{ VH $(\boldsymbol{n}=\mathbf{5 3})$} & \multicolumn{2}{c}{ TAH $(\boldsymbol{n}=\mathbf{1 7 6})$} & \multirow{2}{*}{ t value } & \multicolumn{2}{c|}{$\boldsymbol{p}$ value } \\
\hline Mean & SD & Mean & SD & & ${ }^{*}$ \\
\hline Length of analgesic usage & 5.5 & 1.05 & 9.2 & 1.86 & 13.82 & $<0001^{*}$ \\
\hline Hospital stay & 8.1 & 1.54 & 10.9 & 2.62 & 7.39 & $<0.0001^{*}$ \\
\hline
\end{tabular}

indicates that the difference is significant, SD: Standard deviation

Review of recent studies conclude that surgeons should perform vaginal rather than abdominal hysterectomies whenever possible in order to cut down duration of surgery, complications and the length of hospital stay. Similar to our study results, Dorsey et al in his study showed that duration of surgery was 30 minutes longer for TAH than for $\mathrm{VH}^{6}{ }^{6}$ Similarly eVAL trial showed that average duration of hysterectomy in abdominal group was 50 minutes, vaginal group was 39 minutes, laparoscopic hysterectomy was 84 minutes. ${ }^{7}$

A study by Aniuliene et al showed that significantly higher blood loss was observed during abdominal hysterectomy $(308.5 \mathrm{ml})$ as compared to vaginal (195.3 $\mathrm{ml}$ ), which is comparable to our results. ${ }^{8}$ Similarly Spilsbury et al showed that vaginal hysterectomy was associated with reduced odds of infection and haemorrhage compared with abdominal procedures during the hysterectomy admission. ${ }^{9}$

The hospital stay was longer in TAH group in our study. This finding is consistent with the study done by Consultant et al. ${ }^{10}$ Lambaudie et al compared in an observational study the rate of complications and the duration of the hospital stay between abdominal, vaginal and laparoscopic assisted vaginal hysterectomy in 128 
nulliparous women. The complication rates were no different but the hospital stay was significantly longer for patients who had undergone abdominal hysterctomy. ${ }^{11}$ Benassi et al showed that in the postoperative period, there was a higher demand for analgesics (86\% vs $66 \%, p$ $<.05)$ in the abdominal group as compared with the vaginal group. ${ }^{12}$

Study by Bharatnur et al shows that overall postoperative complications are more in abdominal hysterectomy group than in vaginal hysterectomy, which is similar to our results. ${ }^{13}$ In contrast to our study, bladder injury was higher in vaginal hysterectomy group than abdominal hysterectomy group in study done by Dicker et al. ${ }^{14}$ Whereas studies by Harris et al and Taylor et al showed bowel injury, bladder injury and ureter injury higher in abdominal hysterectomy group than vaginal hysterectomy group. ${ }^{15,16}$

Contraindications for vaginal hysterectomy were usually considered as: nulliparity, history of pelvic surgery and excessive uterine size. However, practices are changing. Vaginal hysterectomy has been reported by several authors as an effective and safe procedure regardless of this contraindications. ${ }^{17-19}$

ACOG and other investigators assert that vaginal hysterectomy is indicated in women with mobile uteri no larger than 12 weeks' gestational size $(\sim 280 \mathrm{~g})$, suggesting that uteri greater than $280 \mathrm{~g}$ are appropriately performed by the abdominal route. ${ }^{20}$

Preoperative documentation of uterine size in vivo can help to prevent abdominal hysterectomy being selected unnecessarily. Kung et al proved that by multiplying the three dimensions of the uterus in centimetres (length $\times$ width $\times$ antero posterior diameter at the fundus) by 0.52 , physicians can estimate the mass of the uterus in grams in order to obtain a more accurate preoperative estimate of uterine size. ${ }^{21}$ But studies done later proved that even larger uterus can be removed vaginally with least complications rate.

Soriano et al performed vaginal/laparoscopic hysterectomy in uterine size $>280 \mathrm{~g}$ and concluded that there was no difference in short-term recovery between patients undergoing vaginal or laparoscopic hysterectomy. No advantage was found performing laparoscopic assisted vaginal hysterectomy in comparison with the standard vaginal hysterectomy. ${ }^{22}$

Consultant et al showed that uterus up to $600 \mathrm{~g}$ can be removed vaginally. ${ }^{10}$ Mean duration (range) of surgery was significantly longer for laparoscopic assisted vaginal hysterectomy compared with vaginal hysterectomy and total abdominal hysterectomy, $102 \mathrm{~min}$ (50-175), $81 \mathrm{~min}$ (35-135) and $68 \mathrm{~min}$ (28-125) respectively. Thus they proved that traditional vaginal hysterectomy to be feasible and the faster operative technique compared with vaginal hysterectomy with laparoscopic assistance.
The vaginal technique is regarded by many gynaecologists as the most cost-effective. ${ }^{23}$ Vaginal hysterectomy performed as a 24-hour day case procedure appears to be as safe as traditional inpatient management. ${ }^{24}$ Hysterectomy by abdominal route is correlated with much higher incidence of intestinal adhesions than other techniques. ${ }^{25}$

\section{CONCLUSION}

Vaginal hysterectomy is associated with quicker recovery, early mobilization, and shorter hospitalization, less operative and post operative morbidity when compared to abdominal hysterectomy.

Funding: No funding sources

Competing interests: None declared

Ethical approval: Not required

\section{REFERENCES}

1. Nieboer TE, Johnson N, Lethaby A, Tavender E, Curr E, Garry R, et al. Surgical approach to hysterectomy for benign gynaecological disease. Cochrane Database Syst Rev 2009;(3):CD003677. doi: 10.1002/14651858.CD003677.pub4.

2. Kovac SR. Clinical opinion: guidelines for hysterectomy. Am J Obstet Gynecol 2004;191:63540.

3. Diker RC, Greenspan JR, Strauss LT, Cowart MR, Scally MJ, Peterson HB, et al. Complications of abdominal and vaginal hysterectomy among women of reproductive age in the United States. The Collaborative Review of Sterilization. Am J Obstet Gynecol 1982;144:841-6.

4. Kovac SR. Guidelines to determine the route of hysterectomy. Obstet Gynecol 1995;85:18-23.

5. Tu FF, Beaumont JL, Senapati S, Gordon TEJ. Route of hysterectomy influence and teaching hospital status. Obstet Gynecol 2009;114:73-8.

6. Dorsey JA, Steinberg EP, Holtz PM. Clinical indications for hysterectomy route; patient characteristics or physician preference? Am J Obstet Gynaecol 1995;173:1452-60.

7. Garry R, Fountain J, Mason S, Napp V, Brown J, Hawe J, et al. The eVALuate study: two parallel randomised trials, one comparing laparoscopic with abdominal hysterectomy and the other comparing laparoscopic with vaginal hysterectomy. BMJ 2004;328:129-33.

8. Aniuliene R, Varzgaliene L, Varzgalis M. A comparative analysis of hysterectomies. Medicina (Kaunas) 2007;43:118-24.

9. Spilsbury K, Hammond I, Bulsara M, Semmens J. Morbidity outcomes of 78,577 hysterectomies for benign reasons over 23 years. BJOG 2008;115:1473-83.

10. Ottosen C, Lingman G, Ottosen L. Three methods for hysterectomy: a randomised, prospective study of short term outcome. BJOG 2000;107:1380-5. 
11. Lambaudie E, Occelli B, Boukerrou M, Crépin G, Cosson M. Vaginal hysterectomy in nulliparous women: indications and limitations. J Gynecol Obstet Biol Reprod 2001;30:325-30.

12. Benassi L, Rossi T, Kaihura CT, Ricci L, Bedocchi L, Galanti B. Abdominal or vaginal hysterectomy for enlarged uteri: a randomized clinical trial. Am J Obstet Gynecol 2002;187:1561-5.

13. Bharatnur S. Comparative Study of Abdominal Versus Vaginal Hysterectomy In Non- Descent Cases. The Internet Journal of Gynecology and Obstetrics 2011;15(2). DOI: 10.5580/293f.

14. Dicker RC, Scally MJ, Greenspan JR, Layde PM, Ory HW, Maze JM, et al. Hysterectomy among women of reproductive age. Trends in the United States, 1970-1978. JAMA 1982;248:323-7.

15. Harris WJ. Early complications of abdominal and vaginal hysterectomy. Obstet Gynecol Surv 1995;50:795-805.

16. Taylor SM, Romero AA, Kammerer-Doak DN, Qualls C, Rogers RG. Abdominal hysterectomy for the enlarged myomatous uterus compared with vaginal hysterectomy with morcellation. Am J Obstet Gynecol 2003;189:1579-83.

17. Figueiredo O, Figueiredo EG, Figueiredo PG, Pelosi MA $3^{\text {rd }}$, Pelosi MA. Vaginal removal of the benign nonprolapsed uterus: experience with 300 consecutive operations. Obstet Gynecol 1999;94:348-51.
18. Sheth SS, Malpani AN. Vaginal hysterectomy following previous caesarean section. Int J Gynecol Obstet 1995;50:165-9.

19. Magos A, Bournas N, Sinha R, Richardson RE, O'Connor H. Vaginal hysterectomy for the large uterus. Br J Obstet Gynaecol 1996;103:246-51.

20. American College of Obstetricians and Gynecologists. Precis IV: An Update in Obstetrics and Gynecology. Washington (DC): The College 1990:197.

21. Kung FT, Chang SY. The relationship between ultrasonic volume and actual weight of pathologic uterus. Gynecol Obstet Invest 1996;42:35-8.

22. Soriano D, Goldstein A, Lecuru F, Darai E. Recovery from vaginal hysterectomy compared with laparoscopy-assisted vaginal hysterectomy. Acta Obstet Gynecol Scand 2001;80:337-41.

23. Dorsey JH, Holtz PM, Griffiths RI, McGrath MM, Steinberg EP. Cost and charges associated with three alternative techniques of hysterectomy. N Engl J Med 1996;335:476-82.

24. Penketh R, Griffiths A, Chawathe S. A prospective observational study of the safety and acceptability of vaginal hysterectomy performed in a 24-hour day case surgery setting vaginal hysterectomy. BJOG 2007;114:430-6.

25. Barmparas G, Branco BC, Schnuriger B, Lam L, Inaba K, Demetriades D. The incidence and risk factors of post-laparotomy adhesive small bowel obstruction. J Gastrointest Surg 2010;14:1619-28.

DOI: $10.5455 / 2320-1770 . i j r \operatorname{cog} 000712$

Cite this article as: Shanthini NF, Poomalar GK, Jayasree M, Bupathy A. Evaluation of complications of abdominal and vaginal hysterectomy. Int J Reprod Contracept Obstet Gynecol 2012;1:7-11. 